\title{
Management of Placenta accreta and its complications in cases of previous cesarean section with placenta previa anterior at Al-Hussein University Hospital
}

\author{
Yassin Asaad Mostafa Abd El-Halim ${ }^{1 *}$ MSc; Farid Ahmed Kassab ${ }^{1}$ MD; \\ Abdel Monsef Abdel Hameed Sedek ${ }^{1}$ MD
}

\author{
*Corresponding Author: \\ Yassin Asaad Mostafa Abd El-Halim \\ yassinnews@yahoo.com
}

Received for publication October 3 , 2020; Accepted November 20, 2020; Published online November 20, 2020.

Copyright 2020 The Authors published by Al-Azhar University, Faculty of Medicine, Cairo, Egypt. All rights reserved. This an openaccess article distributed under the legal terms, where it is permissible to download and share the work provided it is properly cited. The work cannot be changed in anyway or used commercially.

doi: 10.21608/aimj.2020.44790.1332

${ }^{1}$ Obstetrics and Gynecology Department, Faculty of Medicine, Al-Azhar University,Cairo,Egypt.

\begin{abstract}
Background: Every year, 140000 women are estimated to die of postpartum hemorrhage. Placenta accreta has since become a statistically relevant etiology for maternal morbidity and mortality. There has been a 10 -fold increase in the occurrence of placenta accreta since 1970, due to the rising rate of cesarean delivery.

Aim of the work: to determine the occurrence and complications of placenta accreta in instances of prior cesarean sections with placenta previa anterior and outcome of management of these complications at $\mathrm{Al}$ Hussein University Hospital.

Patients and Methods: The study is a prospective cohort study including all cases admitted to $\mathrm{Al}$ Hussein university Hospital diagnosed as placenta previa anterior plus one or more previous cesarean sections during the period from January 2020 to June 2020. The number of cases was 64 cases. 40 cases (63\%) of them were found as placenta previa accreta.

Results: Our findings indicate that the occurrence, risk factors and fetomaternal outcomes of the treatment of patients with placenta accreta at Al Hussein University Maternity Hospital are similar to those of preceding literature.

Conclusion: Placenta previa accreta for the diagnosis, particularly anterior placenta accreta, the sensitivity and specificity of color imagery by Doppler was high since abnormal uteroplacental invasion can be identified with a high degree of trust.
\end{abstract}

Keywords: Morbid Adherent Placenta; Labor Outcome; 2D ultrasound; placenta Previa anterior.

Disclosure: The authors have no financial interest to declare in relation to the content of this article. The Article Processing Charge was paid for by the authors.

Authorship: All authors have a substantial contribution to the article.

\section{INTRODUCTION}

Morbid Adherent Placenta (M.A.P) happens when the myometrium is abnormally invaded by chorionic villi. Depending on histopathology, it is classified into three groups: placenta percreta in which the uterine serosa is penetrated by the chorionic villi, placenta increta in which the chorionic villi invade the myometrium, and placenta accreta in which the chorionic villi are in touch with the myometrium. ${ }^{1}$

It is unclear the precise pathogenesis of placenta accreta. A suggested theory involves a maldevelopment of decidua, excessive invasion of trophoblastic, or a mixture of both. ${ }^{2}$ Defective decidualization, abnormal maternal vascular remodeling, excess trophoblastic invasion, or combinations are known to be the consequences of prior instrumentation. ${ }^{3}$

The occurrence of placenta accreta had risen progressively, reflecting higher rates of caesarean delivery over the last, ${ }^{4}$ For the period 1982 to 2002, an occurrence of 1: 533 births was registered, far higher than previous estimates, varying from 1: 4027 to $1: 2510$ births in the 1970 s to $1980 \mathrm{~s},{ }^{5}$ the occurrence of placenta accreta is expected to further increase. ${ }^{6}$

Placenta accreta is regarded a strong pregnancy complications which could be correlated with intrapartum and postpartum hemorrhage, which is massive and potentially life-threatening. ${ }^{7}$ Placenta accreta is the main trigger of an urgent hysterectomy, and severe uterine hemorrhage may contribute to the necessity for extensive surgery to save lives, including such hysterectomy and major pelvic vessel ligation. ${ }^{8}$

Rebuilding of the urinary bladder or intestine could be required as a result of placental invasion of neighboring organs. In these dramatic conditions, large transfusions of blood and blood products are the norm. Other complications include neonatal death, fistula formation, infection and ureteral damage. $^{9}$

Maternal morbidity was estimated for up to $60 \%$ of women with placenta accreta, and mortality was estimated for up to $7 \%$ of women with placenta accreta. Furthermore, the occurrence of perinatal complications is also raised largely because of preterm birth and tiny fetuses of gestational age. ${ }^{10,11}$ 
Numerous risk indicators were recorded for placenta accreta, which include prior caesarean birth, especially when followed by a coexisting placenta previa, rising numbers of previous caesarean deliveries raise the risk of placenta accreta exponentially. ${ }^{5,12}$ Other predisposing factors have been identified including: multiparity, previous uterine surgery, advanced maternal age, previous uterine curettage, scarred uterus. ${ }^{9,13}$

Placenta accreta is best diagnosed either by sonographic or magnetic resonance imagery techniques in the antenatal period. Several researches have shown the importance of ultrasonography in making this diagnosis, especially at $<20$ weeks of gestation. 14 Regrettably, when the mother experiences persistent vaginal bleeding or extreme vaginal bleeding when an effort has been made to eradicate the placenta or only part of the placenta can be removed, some instances of placenta accreta are diagnosed at the delivery time. ${ }^{15}$

This work aims to determine the occurrence and complications of placenta accreta in instances of prior cesarean sections with placenta Previa anterior and outcome of management of these complications at $\mathrm{Al}$ Hussein university hospital.

\section{PATIENTS AND METHODS}

Type and Duration of the study: The study is a prospective cohort research that involves all cases admitted to $\mathrm{Al}$ Hussein university Hospital departments diagnosed as placenta Previa anterior plus one or more previous cesarean sections during the period from January 2020 to June 2020. The number of cases was 64 cases. 40 cases $(63 \%)$ of them were found as placenta Previa accreta. The research was accepted by the Committee on Ethics and after proper counseling; all women solicited for enrollment and provided written informed consent.

Inclusion criteria include: patients must have placenta Previa anterior. Gestational age: more than 30 weeks at the beginning of the research. Parity: patients must have at least one previous cesarean section.

Exclusion criteria: Patients with unscared uterus, or scared uterus rather than cesarean section. Patients that are normally placenta positioned. Placenta Previa posterior. Coagulopathy.

Diagnosis: The recommended first step for the diagnosis of placenta previa accreta is ultrasound. ${ }^{\mathbf{1 6}}$ The ultrasound used was Philips HD5 at al Hussein University hospital during the period from January 2020 to June 2020.

Preoperative Preparation: Full laboratory tests and if anemia is discovered, it must be corrected properly before delivery. Proper counselling of the patient and her relatives about her case and possible complications as cesarean hysterectomy, bladder, intestinal injury up to death. Patients and her relatives must sign an informed consent form acknowledging that they are aware of risk and complications. Saving of cross matched blood of the same blood group at least two bags of blood and four units of fresh frozen plasma and must be accessible before surgery. Intestinal preparation of the patient should be done. Saving of Intensive Care Unit (ICU) bed before the operation.
Outcomes: Incidence of placenta accreta is much more popular than for placenta increta and percreta. The type and incidence of abnormal placentation in a pooled study of findings from two series comprising a total of 138 histologically verified, abnormally implanted placentas from hysterectomy samples were: Placenta percreta: $7 \%$. Placenta increta: $14 \%$. Placenta accreta: $79 \%{ }^{5}$

Intraoperative Morbidity: In 24 instances of placenta accreta (60\%) Cesarean hysterectomy was performed. In 10 cases (25\%) bladder injury occurred. In 1 case (2.5\%) bowel injury occurred. Intra-operational blood transfusion was obtained in all cases.

The postoperative follow up data were: In 25 (62.5 $\%)$ of the instances with placenta accreta, ICU admission occurred. Transfusion of Postoperative Blood was conducted in 38 cases (95\%) of those with placenta accreta. No complicated cases of DIC or death.

Neonatal outcome: The average gestation period at birth was in weeks' $35.9 \pm 4.546$ gestation (range: 30 39 weeks gestation). Preterm birth occurred in 25 (62.5\%) neonates. The mean 1-min Apgar score was 7.05 in accreta cases (range: $4-8$ ), while the mean 1-min Apger score was 6.65 in non accreta cases (range 4-8). 6 infants (15\%) their mothers have placenta accreta were admitted to the neonatal intensive care unit (NICU), while 5 infants (20.8\%) their mothers have normal placenta admitted to the neonatal intensive care unit (NICU).

Statistical analysis: For the diagnosis of placenta previa accreta, particularly anterior placenta accreta, the sensitivity and specificity of color imagery by Doppler was high since abnormal uteroplacental invasion can be identified with a high degree of trust. The ultrasonography and Doppler indicated morbid adherence in 38 instances (95.2 \%) of the instances accepted with placenta accreta, with specificity of $97.3 \%$, accuracy of $96 \%$, sensitivity of $95.24 \%$, ve predictive value of $92.31 \%$, + ve predictive value of $98.36 \%$.

\section{RESULTS}

\begin{tabular}{|c|c|c|c|}
\hline \multirow{2}{*}{ No. of P.C.S } & \multicolumn{2}{c|}{ Definitive diagnosis } \\
\cline { 3 - 4 } \multicolumn{2}{|c|}{} & $\begin{array}{c}\text { Accreta } \\
(\boldsymbol{n}=\mathbf{4 0})\end{array}$ & $\begin{array}{c}\text { Not accrete } \\
(\boldsymbol{n}=\mathbf{2 4})\end{array}$ \\
\hline \multirow{2}{*}{$\mathbf{1} \mathbf{C S}$} & No. & 2 & 9 \\
\cline { 2 - 4 } & $\%$ & $5.0 \%$ & $37.5 \%$ \\
\hline \multirow{2}{*}{$\mathbf{2 ~ C S}$} & No. & 10 & 5 \\
\cline { 2 - 4 } & $\%$ & $25.0 \%$ & $20.8 \%$ \\
\hline \multirow{2}{*}{$3 \mathbf{C S}$} & No. & 15 & 5 \\
\cline { 2 - 4 } & $\%$ & $37.5 \%$ & $20.8 \%$ \\
\hline \multirow{2}{*}{4 CS } & No. & 11 & 5 \\
\cline { 2 - 4 } & $\%$ & $27.5 \%$ & $20.8 \%$ \\
\hline \multirow{2}{*}{$\mathbf{5}$ CS } & No. & 2 & 0 \\
\cline { 2 - 4 } & $\%$ & $5.0 \%$ & $0.0 \%$ \\
\hline Chi-square test & \multicolumn{3}{|c|}{12.129} \\
\hline p-value & \multicolumn{3}{|c}{$0.016 *$} \\
\hline
\end{tabular}

Table 1 section and the definitive diagnosis of normal and abnormal placenta in all cases. 


\begin{tabular}{|c|c|c|}
\hline Type of complication & No. & \% \\
\hline Operative blood transfusion & 40 & $100.0 \%$ \\
\hline Postoperative blood transfusion & 38 & $95.0 \%$ \\
\hline Cesarean hysterectomy & 24 & $60.0 \%$ \\
\hline ICU admission & 25 & $62.5 \%$ \\
\hline Bladder injury & 10 & $25.0 \%$ \\
\hline Bowel injury & 1 & $2.5 \%$ \\
\hline Death & 0 & $0.0 \%$ \\
\hline
\end{tabular}

Table 2: Intraoperative complications of patients diagnosed as placenta previa accreta.

\begin{tabular}{|c|c|c|}
\hline & No. & $\mathbf{\%}$ \\
\hline Apgar score less than 7 at 5-min & 6 & $15 \%$ \\
\hline RDS & 14 & $35 \%$ \\
\hline NICU & 6 & $15 \%$ \\
\hline Preterm & 20 & $50 \%$ \\
\hline neonatal death & 1 & $2.5 \%$ \\
\hline
\end{tabular}

Table 3: Neonatal outcome in patients diagnosed as placenta previa accreta.

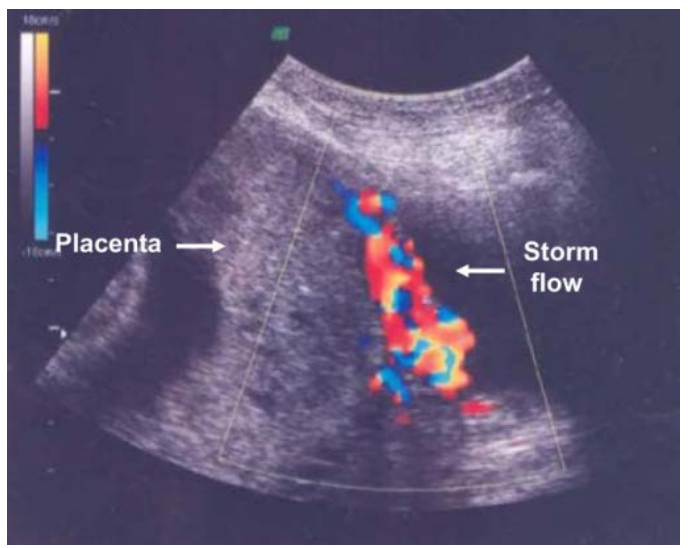

Fig. 1: Hyper vascularity invading myometrium, few lacunae and retroplacental zone loss.

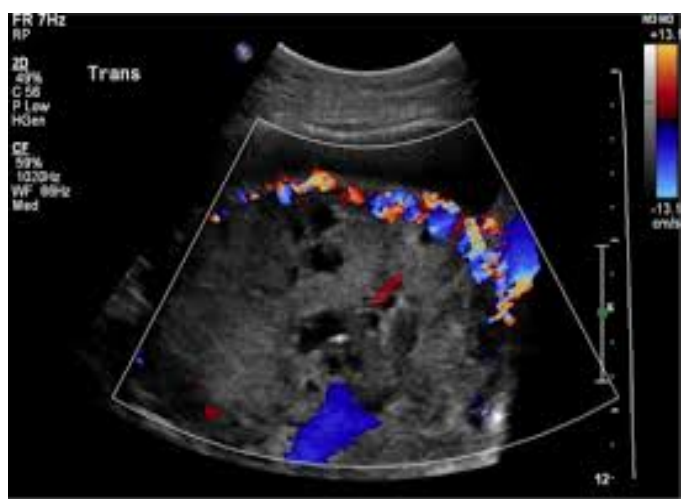

Fig 1: Hyper vascularity in uterine bladder interface.

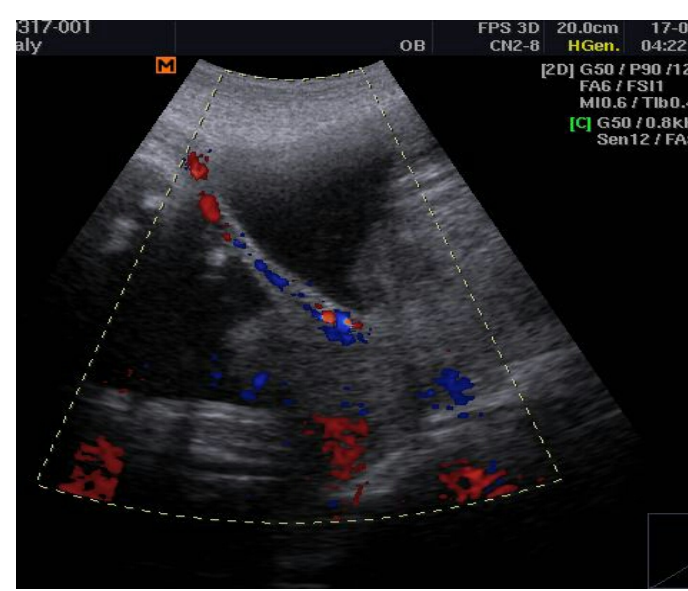

Fig. 2: Uterovesical interface thinning with hyper vascularity (bladder invasion proved intraoperatively \& pathologically).

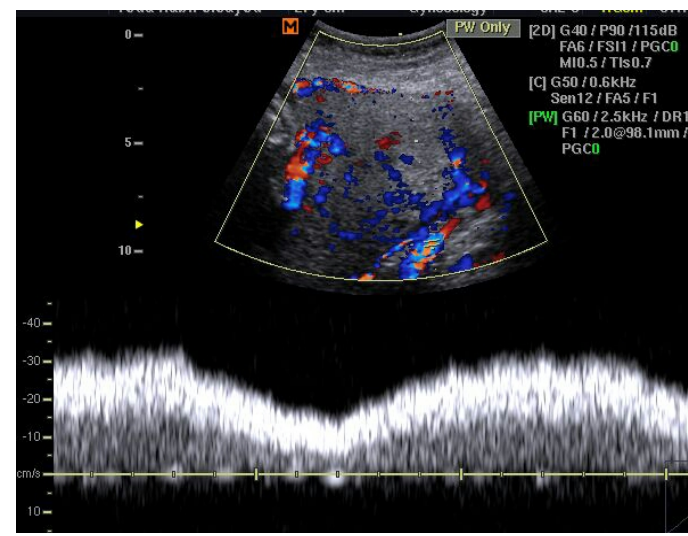

Fig. 3: Diffuse lacunae with turbulent flow of blood.

\section{DISCUSSION}

In our study, the occurrence of placenta accreta with placenta previa anterior in instances with prior cesarean section is 63\%. The noticeable rise in incidence was due in recent years to the rising prevalence of cesarean deliveries.

The result of the study was as follow: Cesarean Hysterectomy was done in $24(60 \%)$ instances of accretion, 10 (25\%) instances of bladder injury, 1 (2.5\%) instance of bowel injury, all instances of intraoperative blood transfusion, 38 (95\%) instances of postoperative blood transfusion and 25 (62.5\%) instances of ICU admission.

In our study the incidences of abnormal placentation: 50\% (28 cases) placenta accreta; 35.7\% (20 cases) placenta increta; and $14.3 \%$ (8 cases) placenta percreta. Therefore, placenta accreta was more common than increta and percreta. ${ }^{5}$ 
There is significant relation between abnormal placenta and number of previous cesarean sections, as whenever the number of previous cesarean section increased the frequency of abnormal placenta also increased. ${ }^{17}$

There is significant relation between the definitive diagnosis of placenta accreta and the antenatal color Doppler diagnosis of placenta accrete. ${ }^{\mathbf{1 8 , 1 9}}$

Color Doppler ultrasound in diagnosis of placenta accreta had specificity $96.8 \%$, sensitivity $82.4 \% .^{20}$

Consideration should always be given to risk of excessive (false positive) hysterectomy or risk of secondary bleeding after attempting placental removal (false negative). ${ }^{21}$

No single diagnostic criterion provides complete certainty of the existence or lack of placenta accreta, ${ }_{22}$ despite modern developments in imaging techniques.

Placenta accreta morbidity is triggered by issues correlated with massive bleeding. In the current study, 64 cases 40 of them definitive diagnosis of abnormal placenta all need intraoperative blood transfusion, while the 24 cases with normal placenta, 11 cases (45.9\%) need intraoperative blood transfusion and 17 cases(70.8\%) need no blood transfusion.

Post-operative blood transfusion needed in 38 cases (95\%) of accreta cases, and 2 cases don't need postoperative blood transfusion, while 7 cases (29.7\%) of normal placenta need blood transfusion, and 17 cases (70\%) need no postoperative blood transfusion. Therefore, blood transfusion is required and a major transfusion is not unusual for these obstetric patients. ${ }^{6}$

No cases in our study complicated with DIC (disseminated intravascular coagulopathy) may be due to the sample size.

As mentioned in the earlier study, other reasons of early morbidity (coagulopathy, bladder injury \& bowel injury, admission to intensive care units) are also elevated in patients suffering from placenta accrete. ${ }^{11}$

In our research, the bladder was injured and repaired in 10 of 40 cases (25\%) all of them with abnormal placenta, while no bladder injury in cases of normal placenta. Bowel injury happen in 1 case only (2.5\%) all have abnormal placenta, while no bowel injury in cases of normal placenta.

In instances of placenta accreta, the occurrence of perinatal complications, primarily due to preterm birth and tiny fetuses of gestational age, is also elevated. ${ }^{11}$ The mean gestational age at delivery was in the present research, $35 \pm 2.819$ weeks' gestation, the mean APGER score in cases of abnormal placenta $7.05 \pm 0.974$ with no significant relation (pvalue0. 105).

Admission in neonatal ICU 6 cases (15\%) of abnormal placenta admitted in NICU, while 34 cases (85\%) not admitted in NICU with no significant relation (p-value0.346).

In up to $7 \%$ of American College of Obstetricians and Gynecologists cases, ${ }^{23}$ maternal mortality recorded: 109 cases of placenta accreta maternal death in 8 cases (7\%), no maternal deaths in the present study. This may be due to the sample size that was insufficient to detect the actual maternal mortality in these obstetric patients, diagnosed preoperatively, adequate blood, very experience surgical team and availability of resources improve maternal and fetal outcome and decrease maternal and fetal mortality.

Limitations of our study include: Limited number of cases of placenta previa accreta attending $\mathrm{Al}$ Hussein University Hospital at the period of the study from January 2020 to June 2020. Patients with accidently discovered placenta accreta during delivery not included in our study as we depend on patient admitted from outpatient clinic during antenatal care period. We may not be assured that all cases have been pathologically confirmed, but the inclusion of clinically identified cases has been limited to those needing active treatment. Large numbers of false positive cases are therefore unlikely to have been included. Another possible drawback is that we cannot be sure that all cases have been decided by us.

\section{CONCLUSION}

In prior cesarean section instances of placenta previa anterior, the incidence of placenta accreta was $63 \%$.

In 24 instances (60\%) of placenta accreta, cesarean hysterectomy was conducted. Bladder injury occurred in 10 cases (25\%). Bowel injury in 1 case (2.5\%). Intraoperative blood transfusions were carried out in all instances of placenta accreta. In 16 cases following spontaneous placenta separation, procedures for uterine preservation (Bakry balloon) were performed.

\section{REFERENCES}

1.Tan CH, Tay KH, Sheah K, Kwek K, Wong K and Tan HK. Perioperative endovascular internal iliac artery occlusion balloon placement in management of placenta accreta. AJR Am J Roentgenol. 2007; 189:1158-63.

2.Garmi G, Salim R, Chulski A. Epidemiology, etiology, diagnosis and management of placenta accreta.Obstetrics and Gynecology.2011; 48:799803.

3.Tantbirojn P, Crum CP and Parast MM: Pathophysiology of placenta accreta. the role of decidua and extravillous trophoblast. Placenta.2008; 29(7):639-45.

4.Hamilton BE, J. Martin A, Ventura SJ, Sutton PD and F Menacker. "Births: preliminary data for National vital Statistics Reports. 2005; 54(8): 1-17.

5.Wu S, Usta M, Kocherginsky M, Yeh M, Hwu H and Hibbard JU. Abnormal placentation: twenty-year analysis. Am J Obstetrics and Gynecology2005:192; .(5) 1458-61

6.Warshak CR, Ramos GA, Eskander R, Benirschke K, Saenz CC, Kelly TF, Moore TR and Resnik R. Effect of predelivery diagnosis in 99 consecutive cases of placenta accreta. Obstetrics and Gynecology. 2007; 115(1):65-9.
Obstetrics and Gynecology 
7.Faranesh R, Shabtai R, Eliezer S and Raed S. "Suggested approach for management of placenta percreta invading the urinary bladder, Obstetrics and Gynecology.2010; 110(2): 512-5.

8.Daskalakis G, Anastasakis E, Papantoniou N, Mesogitis S and Theodora M. "Emergency obstetric hysterectomy," Acta Obstetricia et Gynecologica Scandinavica. 2007; 86(2):223-227.

9.Jacques B and Helen DB. Placenta accreta and the risk of adverse maternal and neonatal outcomes. $J$. Perinat. Med. 2011; 41(2):141-9.

10.Hudon L, Belfort MA and Broome DR. Diagnosis and management of placenta percreta: a review. Obstetrics and Gynecology Survey.2013; 53:509-17.

11.Eller G, Porter TT, Soisson P and Silver RM. Optimal management strategies for placenta," An International Journal of Obstetrics and Gynecology. 2009; 116(5): 648-54.

12.Sivan E, Spira M, Achiron R, Rimon U, Golan G, Mazaki-Tovi S and Schiff E. "Prophylactic pelvic artery catheterization and embolization in women with placenta accreta: can it prevent cesarean hysterectomy?” Am J Perinatol. 2010; 27(6):455461.

13.Miller DA, Chollet JA, Gielchinsky J and Goodwin TM. Clinical risk factors for placenta previaplacenta accreta. Am J Obstetrics and Gynecology. 2010; 4: 177-210.

14.Comstock $\mathrm{CH}$. Antenatal diagnosis of placenta accreta. a review. Ultrasound Obstetrics and Gynecology. 2005; 26:89-96.

15.Kayem G, Johanson J, Grange G and Schmitz A. Clinical aspects and management of morbidly adherent placenta. Eur Clinics Obstetrics and Gynecology. 2006; 2: 139-46.
16.Doumouchtis S and Arulkumaran S. The morbidly adherent placenta: an overview of management options. Acta Obstetrics and Gynecology Scand. 2010; 89(9):1126-33.

17.Silver RM, Landon MB, Rouse DJ, Leveno KJ, Spong CY and Thom EA. Maternal morbidity associated with multiple repeat cesarean deliveries. Obstetrics and Gynecology. 2006; 107 (6): 1226-32.

18.Glaze S, Ekwalanga P, Roberts G, Lange I, Birch C, Rosengarten A, Jarrell J and Ross S. Peripartum hysterectomy. Obstetrics and Gynecology. 2008; 111(3):732-8.

19.Eller AG, Bennett MA, Sharshiner M, Masheter C, Soisson AP, Dodson M and Silver RM. Maternal morbidity in cases of placenta accreta managed by a multidisciplinary care team compared with standard obstetric care. Obstetrics and Gynecology. 2011; 117(2 Pt 1): 331-7.

20.ACOG. Placenta accreta. No. 266. January 2002. American College of Obstetricians and Gynecologists. 2002; 99: 169-70.

21.Shih JC, Palacios Jaraquemada JM, Su YN Shyu MK, Lin CH, Lin SY and Lee CN. Role of threedimensional power Doppler in the antenatal diagnosis of placenta accreta: comparison with gray-scale and color Doppler techniques. Ultrasound Obstetrics and Gynecology. 2009; 33: 193-203.

22.ACOG. Postpartum hemorrhage. Practice Bulletin No. 76. American College of Obstetricians and Gynecologists. 2006; 108:1039-47.

23.ACOG. Placenta accreta. Society for MaternalFetal Medicine American College of Obstetricians and Gynecologists. 2010; 203:430-9. 